\title{
Effect of Sintering Time on The Marginal and Internal Fit of Monolithic Zirconia Crowns Containing 3-4 Mol\% Y2O3
}

\section{Yunus Emre Ozden}

Yeditepe Universitesi Dis Hekimligi Fakultesi

M.Baris Guncu ( $\nabla$ barisguncu@gmail.com )

Hacettepe Universitesi Dis Hekimligi Fakultesi https://orcid.org/0000-0001-6109-2218

\section{Guliz Aktas}

Hacettepe Universitesi Dis Hekimligi Fakultesi

\section{Senay Canay}

Hacettepe Universitesi Dis Hekimligi Fakultesi

\section{Research}

Keywords: Monolithic, zirconia, sintering, marginal, fit

Posted Date: August 30th, 2021

DOI: https://doi.org/10.21203/rs.3.rs-845805/v1

License: (9) This work is licensed under a Creative Commons Attribution 4.0 International License. Read Full License 


\section{Abstract \\ Background}

Short-time sintering may offer advantages including saving time and energy but there is limited evidence on the effect that altering sintering time has on the accuracy of monolithic zirconia crowns. The purpose of this in vitro study was to investigate the effect of shortened sintering time on the marginal and internal fit of 3Y-TZP (three mol\% yttria-stabilized tetragonal zirconia polycrystal) and 4Y-TZP (four mol\% yttriastabilized tetragonal zirconia polycrystal) monolithic crowns.

\section{Methods}

Sixty monolithic zirconia crowns were fabricated for the maxillary first molar tooth on the prefabricated implant abutment. Groups were created according to the material composition: 3Y-TZP Generation 1 (alumina wt; $\leq 0.5 \%,<15 \%$ cubic phase), $3 Y$-TZP Generation 2 (alumina $w t ; \leq 0.05 \%,<15 \%$ cubic phase) and $4 \mathrm{Y}$-TZP (alumina $\mathrm{wt} ; \leq 0.05 \%,>25 \%$ cubic phase). Two different sintering protocols were performed: same final sintering temperature $\left(1500^{\circ} \mathrm{C}\right)$ and various rates of heating $\left(10^{\circ} \mathrm{C} / \mathrm{min}\right.$ and $\left.40^{\circ} \mathrm{C} / \mathrm{min}\right)$, cooling down speed $\left(-10^{\circ} \mathrm{C} / \mathrm{min}\right.$ and $\left.-40^{\circ} \mathrm{C} / \mathrm{min}\right)$, holding time (45 and 120 minutes), and total sintering time (approximately 2 and 7 hours, respectively). The marginal and internal fit of the crowns were determined using the silicone replica technique. Comparisons between groups and sintering times were analyzed using two-way ANOVA. Pairwise multiple comparisons were performed using the t-test $(p<0.05)$.

\section{Results}

The mean marginal gap values of 4Y-TZP zirconia revealed statistically significant increase for the speed sintering protocol $(p<0.0001)$, while no difference was observed between the sintering protocols for the mean marginal gap values of 3Y-TZP groups.

\section{Conclusions}

Although all groups showed clinically acceptable gap values $(<120 \mu \mathrm{m})$, altering the sintering time had an effect on the marginal fit of the crowns manufactured from 4Y-TZP zirconia. Shortening the sintering time may lead to differences within clinically acceptable limits. The manufacturer's recommendations according to material composition should be implemented with care.

\section{Introduction}

Among the all-ceramic restorations, the zirconia structures show statistically higher values of biaxial flexural strength and indentation fracture toughness [1]. Stabilizing oxides added to the crystal lattice of zirconium are of great importance in these superior mechanical properties. Yttrium oxide $\left(\mathrm{Y}_{2} \mathrm{O}_{3}\right.$ or yttria) 
is one of the most commonly used stabilizers for zirconia compositions [2]. Until 2012, only high-strength $3 Y$-TZP Generation 1 (approximately $5.2 \mathrm{wt} \% / 3 \mathrm{~mol} \%$ / alumina wt $\leq 0.5 \%$ ) was used for fabricating restorations from single crowns to multi-unit bridges. To achieve a higher transmittance of light with good long-term stability and high strength, the number and grain size of the alumina $\left(\mathrm{Al}_{2} \mathrm{O}_{3}\right)$ grains were reduced [3];Y-TZP Generation 2 (approximately $5.2 \mathrm{wt} \% / 3 \mathrm{~mol} \%$ / alumina wt $\leq 0.05 \%$ ) was introduced.3 While this attempt maintained the zirconia's mechanical properties, the optical characteristics were still insufficient [4]. The translucent dental zirconias involved increasing the content of yttria [2]. Due to the increased yttria content, cubic phase occurs alongside metastable tetragonal phase. The quantity of the cubic phase increases around $25 \%$ in $4 Y$ - TZP. The grains in 4Y-TZP are larger than in 3Y-TZP, resulting in fewer grain boundaries, less birefringence and scattering of light [5].

With the introduction of modified translucent zirconia materials, the use of fully anatomic zirconia crowns and FDPs in the posterior region has become a new restorative option [6]. Monolithic zirconia offers two advantages: minimal tooth reduction since there is no need for space clearance for the veneering material [7]. and reduced cost and time for the production compared with porcelain-fused-tozirconia [8]. Although the monolithic approach is not new, monolithic Y-TZP posterior restorations have a significant advantage due to their high fracture resistance $[9,10]$.

Zirconia restorations are milled from premanufactured blocks using the CAD/CAM technology. Commercially, these blocks are available in two process stages: presintered and fully sintered [11]. Milling from presintered blocks is easier, faster, and causes lesser wear on the machining tools. Due to these advantages, presintered blocks are popular for the fabrication of zirconia structures in the world market. When presintered blocks are used, the material must be sintered at a high temperature in order to obtain sufficient strength after the milling process. During the sintering process, the material shrinks making the framework denser and stronger [12]. Moreover, sintering temperature and duration affects the microstructure of the Y-TZP. The mean grain size in 3Y-TZP increases with the sintering temperature and time $[13,14]$. The process should be performed at sufficiently low temperatures to avoid the occurrence of a dual cubic-tetragonal microstructure but also at sufficiently high temperatures to obtain fully dense materials [14].

Short-time sintering may offer several advantages including improved productivity as well as saving time and energy. A few studies have been conducted to examine the effect of sintering time on the mechanical properties of 3Y-TZP [15-18]. The previous studies have been controversial. While Juntavee et al. [18] suggested that prolonging the sintered-holding time lead to enhancing the flexural strength of the translucent monolithic zirconia, Ebeid et al. [15] reported that biaxial flexural strength is not affected by changes in the sintering times. Moreover, Ersoy et al. [16] advised the combination of high temperature and short sintering time to increase the flexural strength of zirconia.

While one of the most important factors affecting the survival of restoration is durability of the material, the other is marginal and internal fit of restoration. Marginal accuracy of zirconia restorations has been investigated in various studies [19-21]. Only a few studies have investigated the effect of short-term 
sintering on the marginal accuracy of monolithic zirconia containing 3 mol $\% \mathrm{Y}_{2} \mathrm{O}_{3}[22,23]$. The aim of this study was to investigate the effect of two different sintering times on the marginal and internal fit of three generations monolithic zirconia crowns. The null hypothesis was that there is no difference in the accuracy of restorations with different sintering times.

\section{Material And Methods}

Sixty prefabricated abutments (solid abutments, $4 \mathrm{~mm}$ height; Straumann, Basel, Switzerland) were used to evaluate the marginal and internal accuracy of monolithic crowns. The abutments were connected to their corresponding implant analogs with screwdrivers and tightened with $35 \mathrm{Ncm}$ torque with torque control devices. İmplant analogs were embedded into epoxy resin (Morapox, Moravia) with a dental surveyor (Paraskop M, Bego $\mathrm{GmbH}$ ). Each abutment was scanned with the Dental Wings 7series 3D Scanners (Dental Wings Inc., Montreal, Canada) after a scannable surface was achieved by powder spraying (Cerec Optispray, Sirona Dental Systems, Bensheim, Germany). A maxillary first molar tooth was designed with DWOS (Dental Wings Inc., Montreal, Canada) with a simulated cement space of $25 \mu$ around the margins, and additional cement space of $50 \mu$ from $1 \mathrm{~mm}$ above the finish lines of the abutment (Fig. 1) [24.] Groups were created according to the material composition (according to the manufacturer's catalog): 3Y-TZP Generation 1 (alumina wt; $\leq 0.5 \%$, cubic phase; $<15 \%$ ); Lava ${ }^{\text {TM }}$ Zirconia (3M ESPE, Neuss, Germany), 3Y-TZP Generation 2 (alumina wt; $\leq 0.05 \%$, cubic phase; $<15 \%$ ); inCoris TZI (Dentsply Sirona, Bensheim, Germany) and 4Y-TZP (alumina wt; $\leq 0.05 \%$, cubic phase; $>25 \%$ ); Katana ${ }^{\text {TM }}$ Zirconia STML (Kuraray Noritake Dental, Aichi, Japan). Two different sintering protocols were followed according to the instructions $(n=10)($ Table 1$)$.

Table 1

Performed sintering's according to the protocols.

\begin{tabular}{|lllllll|}
\hline $\begin{array}{l}\text { Sintering } \\
\text { protocol }\end{array}$ & $\begin{array}{l}\text { Starting } \\
\text { Degree }\end{array}$ & $\begin{array}{l}\text { Heating } \\
\text { rate }\end{array}$ & $\begin{array}{l}\text { Sintering } \\
\text { temperature }\end{array}$ & $\begin{array}{l}\text { Holding } \\
\text { time }\end{array}$ & $\begin{array}{l}\text { Cooling } \\
\text { down } \\
\text { speed }\end{array}$ & $\begin{array}{l}\text { Total sintering time } \\
\text { (approximately) }\end{array}$ \\
\hline $\begin{array}{l}\text { Long - } \\
\text { term }\end{array}$ & $\begin{array}{l}\text { Room } \\
\text { temperature }\end{array}$ & $\begin{array}{l}10^{\circ} \mathrm{C} / \\
\min \end{array}$ & $1500^{\circ} \mathrm{C}$ & $\begin{array}{l}120 \\
\text { minutes }\end{array}$ & $\begin{array}{l}-10^{\circ} \mathrm{C} / \\
\mathrm{min}\end{array}$ & 7 hours \\
\cline { 1 - 1 } & & $\begin{array}{l}40^{\circ} \mathrm{C} / \\
\mathrm{min}\end{array}$ & & $\begin{array}{l}45 \\
\text { minutes }\end{array}$ & $\begin{array}{l}-40^{\circ} \mathrm{C} / \\
\mathrm{min}\end{array}$ & 2 hours \\
\hline
\end{tabular}

The marginal and internal fit of the specimens were determined with a silicone replica technique [25]. A light-body type impression material (Vinylsiloxanether Identium Light; Kettenbach GmbH \& Co KG) was applied to the inner surface of the crowns. Restorations were placed on the abutments with finger pressure for $5 \mathrm{~s}$ and then subjected to a $50 \mathrm{~N}$ load $(5 \mathrm{~kg})$ for $5 \mathrm{~min}$. After the impression material polymerized, the restorations were removed from the abutment, leaving the impression material intact. To stabilize the thin elastomer layer, which represented the discrepancy between the abutment and the restoration, a light-body type of polyvinyl siloxane impression material (Elite HD + Light Body Fast Set; Zhermack SpA) was applied. The silicone replicas were sectioned with a sharp blade in two directions, 
buccolingually and mesiodistally. Measurements were performed from each quarter part of the replica as follows: one marginal, two axial (mid-distance of the axial wall and the junction between the occlusal and axial area), and one occlusal (in the center of occlusal area). In total, 16 measurements (four marginal, eight axial, and four occlusal) were conducted for the crowns. All the measurements were recorded by using a light microscope (SZ61/SZ51; Olympus Corp) at $\times 45$ magnification, and a digital measurement program (ImageJ; National Institutes of Health). The comparison between groups and sintering times were analyzed by using the two-way ANOVA. Levene's test was used to assess the assumption of homogeneity of variances. Pairwise multiple comparisons were performed with the t-test. The significance level was set at 0.05 .

\section{Results}

The mean marginal gap values are given in Fig. 3. The two-way ANOVA test revealed a statistical significance among the groups in both long term and speed sintering protocols $(p<0.0001)$. When the impact of sintering time on the crowns was evaluated, statistical significance was detected only in $4 \mathrm{Y}$ TZP group $(p<0.0001)$. The mean total gap values that indicate cement film thickness are given in Fig. 4 . While the mean total gap values were comparable in the long-term sintering protocol $(p>0.05)$, statistical significance was detected among the groups in the speed sintering protocol $(p<0.0001)$. When the impact of sintering time on the crowns was evaluated, statistical significance was detected in 3Y-TZP Generation $2(p=0.0016)$ and 4Y-TZP $(p<0.0001)$.

\section{Discussion}

The null hypothesis, that there is no difference in the accuracy of restorations with different sintering times, was partially rejected. The mean marginal gap values of 4Y-TZP were increased if the sintering time is shortened while 3Y-TZP groups were not affected by this situation.

A few studies focused on the effect of changes in the sintering time on the marginal fit of monolithic zirconia crowns $[23,26]$. Khaledi et al. [23] reported that different sintering times does not alter the marginal fit of the zirconia copings fabricated from 3Y-TZP presintered blocks. The findings are in accordance with the present study for the 3Y-TZP group. On the other hand, in a previous study focused on 3Y-TZP monolithic crowns it was showed that the marginal gap values of speed sintering ( 2 hours, 55 minutes in total) groups were higher than the corresponding combinations of standart sintering ( 9 hours, 50 minutes in total) [26]. The differences between the findings of these studies may be due to the thickness of restorations.

4Y-TZP zirconia was launched in 2015 with the indication of full-contour restoration and framework material in the posterior region due to adequate mechanical strength with improved optical properties. The present study revelaed a statistically significant increase in the marginal gap values in 4Y-TZP group for the speed sintering protocol. The creep rate of polycrystalline ZrO2 with different composition may be more sensitive to creep and distortion during the sintering process [27]. Increasing yttria content influence 
the number of grain boundaries that controls the major physical properties such as light transmission and flexural strength [28]. Moreover, material composition of monolithic zirconia crowns affect internal fit, crown margin quality [29].

Zirconia restorations produced by soft machining of the presintered blocks are sintered at temperatures varying between 1350 and $1550 \circ \mathrm{C}$, depending on the manufacturer. In general, it can be stated that sintering temperatures of $1,600^{\circ} \mathrm{C}$ onwards lead to a decrease in flexural strength. 14 The sintering conditions have a strong impact on the mechanical properties of the definitive product [30]. Novel speed sintering protocols have been developed to meet the demand for chairside one-visit restorations [31]. Altering the sintering parameters was attempted to shorten the zirconia sintering process by inducing rapid heating rate and lowering the sintered-holding time [18].

The effect of altering the sintering conditions on the mechanical and optical properties of zirconia frameworks has been the subject of many studies [15, 16, 18, 31-33]. The reported results are inconclusive, and whether increasing the sintering temperature and/or prolonged sintering-holding time enhances translucency [32-34] remains unclear [13, 31 31]. For improved productivity, shortened dwell time is beneficial, but it may result in poor mechanical behavior compared with long-term sintering [18]. On the other hand, encouraging results of a previous study showed that the combination of high sintering temperature and short sintering time increases the flexural strength of zirconia [16]. Additionally, it was reported that biaxial flexural strength is not affected by altering the sintering conditions $[15,33]$. More research is needed to assess the effect of sintering times and temperatures on the mechanical and optical properties of zirconia prostheses.

Shrinkage occurring in presintered blocks during the sintering process has been studied previously [ 12 , 35]. The milling machine software is programmed to compensate for the shrinkage percentage of the partially sintered zirconia blocks after sintering [30]. Rezende et al. [12] evaluated dimensional changes brought about by sintering of the Y-TZP blocks and reported a significant difference among the groups for the internal fit of copings. Additionally, the sintering shrinkage rate reported by the manufacturer was different from that obtained experimentally. Limited data are available to compare those with results of the present study. However, it is noteworthy that one of the two groups with a significant difference showed an increase in the gap values, whereas shrinkage occurred in the other group. This may be because the density difference of presintered zirconia blocks affects linear sintering shrinkage [35].

Non-uniform sintering shrinkage might lead to a misfit of the restorations. The cement space has a significant effect on the marginal fit of monolithic zirconia crowns. Marginal discrepancy values increase when the cement space decreases. As the cement space was set at $50 \mu \mathrm{m}$ using the software, the marginal discrepancy was $53 \mu \mathrm{m}$ in this study. Conversely, when the cement space was set at $30 \mu \mathrm{m}$, the marginal discrepancy was $85 \mu \mathrm{m}$ [24]. Larger internal misfit may also affect the success of ceramic crowns [36]. However, there is no consensus on the limit for clinically acceptable values of internal fit. The mean variation in the crowns tested in the present study is in accordance with that reported in previous studies [29, 37]. Additionally, marginal gap values of all groups were less than $120 \mu \mathrm{m}$. The widest 
marginal gap measured was $78 \pm 9 \mu \mathrm{m}$, and the lowest was $33 \pm 6 \mu \mathrm{m}$. Larger frameworks might result in a higher misfit of the prosthesis.38 Further studies are required to assess the effect of sintering conditions on the accuracy of new generations of monolithic zirconia restorations.

\section{Conclusions}

Within the limitations of the present study:

- All groups showed clinically acceptable gap values $(<120 \mu \mathrm{m})$.

- Altering the sintering time had no effect on the marginal fit of the crowns manufactured from 3Y-TZP groups.

- Shortening the sintering time for 4Y-TZP monolithic crowns resulted in significantly larger gap values.

\section{Abbreviations}

3Y-TZP: Three mol\% yttria-stabilized tetragonal zirconia polycrystal

4Y-TZP : Four mol\% yttria-stabilized tetragonal zirconia polycrystal

\section{Declarations}

Acknowledgements: This study was supported by Hacettepe University Scientific Research Projects Coordination Unit (014 D07 201 001-676)

Authors' contributions : YEO carried out the measurements and contributed to analysis, collected and interpreted the data and wrote the manuscript. MBG coordinated the research project, participated in the interpretation of the results, drafted the manuscript, and critically revised the manuscript. GA participated in the interpretation of the results, contributed to the data acquisition and analysis, and critically revised the manuscript. SC participated in the interpretation of the results, and drafted the manuscript and critically revised the manuscript. All authors read and approved the final manuscript.

Funding: This study was supported by Hacettepe University Scientific Research Projects Coordination Unit (014 D07 201 001-676)

Availability of data and materials: The datasets used and/or analysed during the current study are available from the corresponding author on reasonable request.

Ethics approval and consent to participate: Not applicable.

Consent for publication: Not applicable.

Competing interests: The authors declare that they have no competing interests 


\section{References}

1. Yilmaz $\mathrm{H}$, Aydin $\mathrm{C}$, Gul BE. Flexural strength and fracture toughness of dental core ceramics. $J$ Prosthet Dent. 2007;98:120-8. https://doi.org/10.1016/S0022-3913(07)60045-6.

2. Stawarczyk B, Keul C, Eichberger M, Figge D, Edelhoff D, Lumkemann N. Three generations of zirconia: From veneered to monolithic. Part I. Quintessence Int. 2017;48:369-80. https://doi.org/10.3290/j.qi.a38057.

3. Burgess JO. Zirconia: The Material, Its Evolution, and Composition.2018;39:4-8.

4. Zhang Y, Lawn BR. Novel Zirconia Materials in Dentistry. J Dent Res. 2018;97:140-7. https://doi.org/10.1177/0022034517737483.

5. Basu B, Kalin M. Tribology of ceramics and composites: a materials science perspective. Hoboken: Wiley; 2011.

6. Konstantinidis I, Trikka D, Gasparatos S, Mitsias ME. Clinical Outcomes of Monolithic Zirconia Crowns with CAD/CAM Technology. A 1-Year Follow-Up Prospective Clinical Study of 65 Patients. Int J Env Res Pub He 2018;15. https://doi.org/ 10.3390/ijerph15112523.

7. Nakamura K, Harada A, Inagaki R, Kanno T, Niwano Y, Milleding P, et al. Fracture resistance of monolithic zirconia molar crowns with reduced thickness. Acta Odontol Scand 2015;73:602-8. https://doi.org/ 0.3109/00016357.2015.1007479.

8. Ferrari M, Sorrentino R, Cagidiaco MC, Goracci C, Vichi A, Gherlone E, et al. Short-term clinical performance of zirconia single crowns with different framework designs: 3-year clinical trial. Am J Dent. 2015;28:235-40.

9. Habibi Y, Dawid MT, Waldecker M, Rammelsberg P, Bomicke W. Three-year clinical performance of monolithic and partially veneered zirconia ceramic fixed partial dentures. J Esthet Restor Dent 2020. https://doi.org/ 10.1111/jerd.12568.

10. Tang ZY, Zhao XY, Wang H, Liu B. Clinical evaluation of monolithic zirconia crowns for posterior teeth restorations. Medicine 2019;98. https://doi.org/10.1097/md.0000000000017385.

11. Komine F, Blatz M, Matsumura H. Current status of zirconia-based fixed restorations. J Oral Sci 2010;52:531-9. https://doi.org/ 10.2334/josnusd.52.531.

12. Rezende CEE, Borges AFS, Macedo RM, Rubo JH, Griggs JA. Dimensional changes from the sintering process and fit of Y-TZP copings: Micro-CT analysis. Dent Mater. 2017;33:E405-E13. https://doi.org/10.1016/j.dental.2017.08.191.

13. Kim MJ, Ahn JS, Kim JH, Kim HY, Kim WC. Effects of the sintering conditions of dental zirconia ceramics on the grain size and translucency. J Adv Prosthodont. 2013;5:161-6. https://doi.org/10.4047/jap.2013.5.2.161.

14. Stawarczyk B, Ozcan M, Hallmann L, Ender A, Mehl A, Hammerlet CHF. The effect of zirconia sintering temperature on flexural strength, grain size, and contrast ratio. Clin Oral Invest 2013;17:269 - 74. https://doi.org/ 0.1007/s00784-012-0692-6. 
15. Ebeid K, Wille S, Hamdy A, Salah T, El-Etreby A, Kern M. Effect of changes in sintering parameters on monolithic translucent zirconia. Dent Mater 2014;30:E419-E24. https://doi.org/ 10.1016/j.dental.2014.09.003.

16. Ersoy NM, Aydogdu HM, Degirmenci BU, Cokuk N, Sevimay M. The effects of sintering temperature and duration on the flexural strength and grain size of zirconia. Acta Biomater Odontol Scand 2015;1:43-50. https://doi.org/ 10.3109/23337931.2015.1068126.

17. Inokoshi M, Zhang F, De Munck J, Minakuchi S, Naert I, Vleugels J, et al. Influence of sintering conditions on low-temperature degradation of dental zirconia. Dent Mater 2014;30:669-78. https://doi.org/ 10.1016/j.dental.2014.03.005.

18. Juntavee $\mathrm{N}$, Attashu S. Effect of different sintering process on flexural strength of translucency monolithic zirconia. J Clin Exp Dent. 2018;10:e821-e30. https://doi.org/10.4317/jced.54749.

19. Habib SR, Al Otaibi AK, Al Anazi TA, Al Anazi SM. Comparison between five CAD/CAM systems for fit of zirconia copings. 2018;49:437-44. https://doi.org/10.3290/j.qi.a40354.

20. Habib SR, Asiri W, Hefne MJ. Effect of anatomic, semi-anatomic and non-anatomic occlusal surface tooth preparations on the adaptation of zirconia copings. J Adv Prosthodont. 2014;6:444-50. https://doi.org/10.4047/jap.2014.6.6.444.

21. Torabi K, Vojdani M, Giti R, Taghva M, Pardis S. The effect of various veneering techniques on the marginal fit of zirconia copings. 2015;7:233-9. https://doi.org/10.4047/jap.2015.7.3.233.

22. Ahmed WM, Troczynski T, McCullagh AP, Wyatt CCL, Carvalho RM. The influence of altering sintering protocols on the optical and mechanical properties of zirconia: A review. 2019;31:423-30. https://doi.org/10.1111/jerd.12492.

23. Khaledi AAR, Vojdani M, Farzin M, Pirouzi S, Orandi S. The Effect of Sintering Time on the Marginal Fit of Zirconia Copings. J Prosthodont. 2019;28:E285-E9. https://doi.org/10.1111/jopr.12731.

24. Kale E, Seker E, Yilmaz B, Ozcelik TB. Effect of cement space on the marginal fit of CAD-CAMfabricated monolithic zirconia crowns. J Prosthet Dent. 2016;116:890-5. https://doi.org/10.1016/j.prosdent.2016.05.006.

25. Xu D, Xiang N, Wei B. The Marginal Fit of Selective Laser Melting-Fabricated Metal Crowns: An in Vitro Study. J Prosthet Dent. 2014;112:1437-40. https://doi.org/10.1016/j.prosdent.2014.05.018.

26. Ahmed WM, Abdallah MN, McCullagh AP, Wyatt CCL, Troczynski T, Carvalho RM. Marginal Discrepancies of Monolithic Zirconia Crowns: The Influence of Preparation Designs and Sintering Techniques. J Prosthodont. 2019;28:288-98. https://doi.org/10.1111/jopr.13021.

27. Pelleg J. Creep in Ceramic. Springer; 2017.

28. Jansen JU, Lumkemann N, Letz I, Pfefferle R, Sener B, Stawarczyk B. Impact of high-speed sintering on translucency, phase content, grain sizes, and flexural strength of 3Y-TZP and 4Y-TZP zirconia materials. J Prosthet Dent. 2019;122:396-403. https://doi.org/10.1016/j.prosdent.2019.02.005.

29. Schriwer C, Skjold A, Gjerdet NR, Oilo M. Monolithic zirconia dental crowns. Internal fit, margin quality, fracture mode and load at fracture. Dent Mater. 2017;33:1012-20. https://doi.org/10.1016/j.dental.2017.06.009. 
30. Denry I, Kelly JR. State of the art of zirconia for dental applications. Dent Mater 2008;24:299-307. https://doi.org/0.1016/j.dental.2007.05.007.

31. Kaizer MR, Gierthmuehlen PC, dos Santos MBF, Cava SS, Zhang Y. Speed sintering translucent zirconia for chairside one-visit dental restorations: Optical, mechanical, and wear characteristics. Ceram Int. 2017;43:10999-1005. https://doi.org/10.1016/j.ceramint.2017.05.141.

32. Attachoo S, Juntavee N. Role of sintered temperature and sintering time on spectral translucence of nano-crystal monolithic zirconia. J Clin Exp Dent. 2019;11:e146-e53. https://doi.org/10.4317/jced.55497.

33. Sen N, Sermet IB, Cinar S. Effect of coloring and sintering on the translucency and biaxial strength of monolithic zirconia. J Prosthet Dent 2018;119:308 e1-e7. https://doi.org/10.1016/j.prosdent.2017.08.013.

34. Jiang L, Liao YM, Wan QB, Li W. Effects of sintering temperature and particle size on the translucency of zirconium dioxide dental ceramic. J Mater Sci-Mater M. 2011;22:2429-35. https://doi.org/10.1007/s10856-011-4438-9.

35. Oh GJ, Yun KD, Lee KM, Lim HP, Park SW. Sintering behavior and mechanical properties of zirconia compacts fabricated by uniaxial press forming. J Adv Prosthodont. 2010;2:81-7. https://doi.org/10.4047/jap.2010.2.3.81.

36. Rezende CEE, Borges AFS, Gonzaga CC, Duan YY, Rubo JH, Grigg JA. Effect of cement space on stress distribution in Y-TZP based crowns. Dent Mater. 2017;33:144-51. https://doi.org/10.1016/j.dental.2016.11.006.

37. Rau SA, Raedel M, Mikeli A, Raedel M, Walter MH. Clinical Fit of Monolithic Zirconia Single Crowns. Int J Prosthodont. 2018;31:443-5. https://doi.org/10.11607/ijp.5512.

38. Kunii J, Hotta Y, Tamaki Y, Ozawa A, Kobayashi Y, Fujishima A, et al. Effect of sintering on the marginal and internal fit of CAD/CAM-fabricated zirconia frameworks. Dent Mater J. 2007;26:820-6. https://doi.org/10.4012/dmj.26.820.

\section{Figures}

\section{Figure 1}

Designed crown on the prefabricated abutment. 


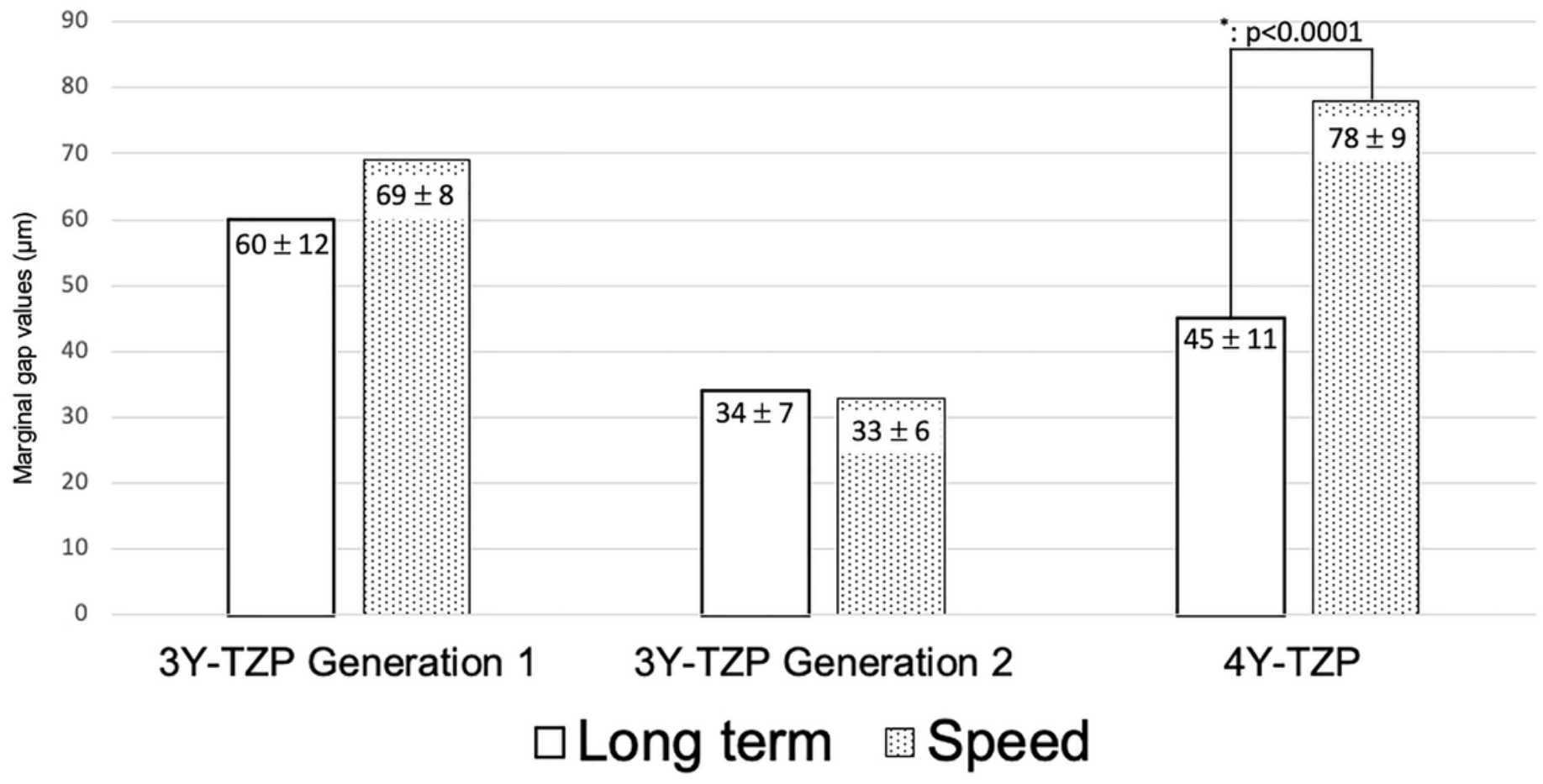

Figure 2

Mean marginal gap values of monolithic zirconia crowns.

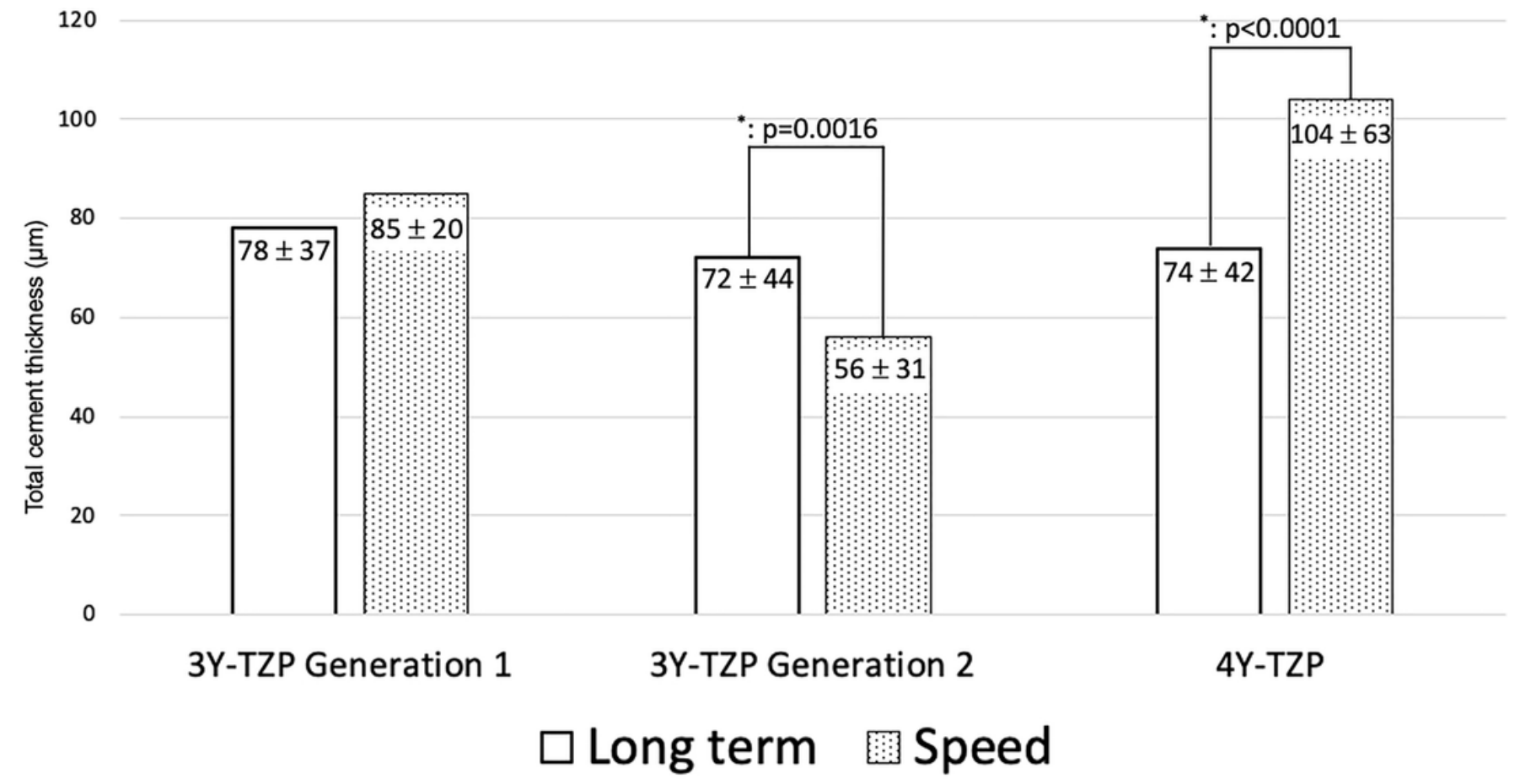

Figure 3 
Mean total gap values of monolithic zirconia crowns.

Page $12 / 12$ 